\title{
Método para verificação automatizada de requisitos em empreendimentos Habitacionais de Interesse Social
}

\author{
Method for automated requirement checking in social \\ housing projects
}

\section{Guilherme von der Heyde Fernandes Carlos Torres Formoso Patrícia Tzortzopoulos-Fazenda}

\section{Resumo

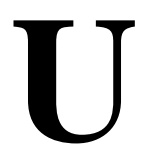

ma das possíveis estratégias para melhorar a qualidade dos empreendimentos de construção é o uso de Building Information Modelling (BIM), que envolve inovações relacionadas à tecnologia da informação e mudanças em processos críticos. Na habitação de interesse social no Brasil, um dos desafios enfrentados é a necessidade de avaliar em um prazo relativamente curto um grande número de projetos submetidos para financiamento, principalmente após a criação do programa Minha Casa, Minha Vida. A verificação automatizada de projetos tem sido apontada na literatura como uma das principais oportunidades para o uso de BIM. A avaliação de projetos por órgãos governamentais é com frequência baseada principalmente na experiência dos técnicos responsáveis, e pode haver falta de uniformidade nos critérios adotados, além de ser um processo demorado e custoso. O objetivo deste trabalho consiste em propor um método automatizado de verificação de requisitos para projetos de empreendimentos de habitação de interesse social com o uso de BIM. Esse método foi testado em dois empreendimentos habitacionais do programa Minha Casa, Minha Vida e foi comparado com o processo realizado manualmente. O estudo também apresenta contribuições referentes à natureza dos requisitos para esse tipo de empreendimento e discute as mudanças de processo necessárias para o uso de sistemas computacionais de verificação automatizada.

Palavras-chave: Verificação automatizada. BIM. Minha Casa, Minha Vida. Habitação de Interesse Social.

\section{Abstract}

One of the possible strategies for improving the quality of construction projects is the use of Building Information Modelling (BIM), which involves innovations in information technology and changes in critical processes. In the social housing sector in Brazil, the need to evaluate a large number of projects proposed for funding in a very short time frame is a major challenge. Automated design checking has been pointed out as one of the main opportunities for the use of BIM in the building industry. The evaluation of social housing projects by governmental bodies is often based mainly on the experience of construction professionals, which may result in lack of uniformity in the criteria adopted, and in a time consuming and costly process. The aim of this research study is to propose a method for automated checking of requirements for the design of social housing projects by using BIM. This method was tested in two housing projects funded by the Minha Casa, Minha Vida programme, and compared to the manual process. This investigation also makes contributions related to the understanding of the nature of the requirements involved in this type of project, and discusses the process changes needed to introduce automated design checking.

Recebido em 28/06/17 Aceito em 17/01/18
Keywords: Design checking. BIM. Code-checking. Social housing projects. Low income housing. 


\section{Introdução}

O programa Minha Casa, Minha Vida (MCMV), ao buscar reduzir de forma expressiva o déficit habitacional brasileiro (INSTITUTO..., 2013), estabeleceu metas numéricas expressivas em termos de unidades produzidas. Ao mesmo tempo, foi estabelecido um conjunto de especificações mínimas a serem atendidas pelos empreendimentos habitacionais de interesse social (BRASIL, 2012). Nesse sentido, o programa MCMV representou um desafio para os agentes envolvidos no segmento, tanto pela velocidade na realização de um grande número de empreendimentos, como pela necessidade de alcançar níveis de especificação adequados.

Uma das possíveis estratégias para lidar com a grande quantidade de informações e a necessidade de reduzir os prazos de elaboração e aprovação de projetos é o uso de Building Information Modelling ${ }^{1}$ (BIM), que combina o uso de tecnologia da informação com mudanças nos processos na cadeia de suprimentos (LAAKSO; KIVINIEMI, 2012). A partir da modelagem e simulação de produtos e processos, algumas tarefas podem ser automatizadas, o que facilita a manipulação das informações (SINGH; NING, 2012).

Contudo, uma das principais dificuldades para a implementação de BIM é o fato de a indústria da construção ser muito fragmentada, o que dificulta a implementação de mudanças no âmbito da cadeia de suprimentos (SMITH; TARDIF, 2009). Nesse sentido, o Estado, por meio de seu poder de compra e também por seu papel de financiador e regulamentador, pode contribuir substancialmente para a disseminação de BIM na indústria (LAAKSO; KIVINIEMI, 2012). Mesmo assim, o incentivo por parte do poder público brasileiro para o uso de BIM tem sido relativamente tímido em comparação com outros países, como Cingapura (NOVACITYNETS, 2013), EUA (FIATECH, 2014) e Grã-Bretanha (BRITISH..., 2012).

No contexto da habitação de interesse social no país, a Caixa Econômica Federal (Caixa) tem cumprido com o papel de indutora de melhorias no setor da construção, como agente financeiro de programas habitacionais brasileiros. Tal poder indutor tem respaldo na participação dessa instituição financeira no crédito imobiliário, responsável por mais de $70 \%$ do mercado nacional e agente das políticas públicas do Governo Federal

${ }^{1}$ Building Information Modeling é traduzido para português como Modelagem de Informações da Construção.
(CAIXA, 2014). Um dos desafios enfrentados pela Caixa na realização de empreendimentos habitacionais é a necessidade de avaliar em um prazo relativamente curto um grande número de projetos submetidos para financiamento em relação a uma ampla gama de requisitos. Isso ocorreu principalmente após a criação do programa MCMV (BALDAUF, 2013).

De fato, a verificação automatizada de projetos por parte de órgãos governamentais tem sido apontada na literatura como uma das principais oportunidades para o uso de BIM no subsetor Edificações (EASTMAN et al., 2011; LAAKSO; KIVINIEMI, 2012). Esse problema tem sido amplamente discutido no setor, uma vez que o processo de verificação é carente de sistematização, sendo normalmente realizado manualmente, com base em plantas-baixas, cortes e fachadas impressos (LEE, 2011; MARTINS; MONTEIRO, 2012). Isso resulta no aumento da possibilidade de erros, além da excessiva dependência no conhecimento de profissionais especializados nesse tipo de verificação (TAN; HAMMAD; FAZIO, 2010). Dessa forma, como muitas decisões são baseadas na experiência e expertise desses profissionais, pode ocorrer falta de uniformidade entre eles, além de ser um processo demorado e custoso tanto para os órgãos responsáveis por essa verificação quanto para os proponentes (ZHONG et al., 2012; ZHANG et al., 2013).

Atualmente, existem ferramentas computacionais de verificação automatizada de requisitos disponíveis no mercado que aplicam um conjunto de procedimentos à informação disponível nos modelos BIM (PAUWELS et al., 2011). São sistemas versáteis pelo fato de verificarem a aderência das características de um modelo a uma ampla gama de padrões preestabelecidos, podendo ser utilizadas para uma simples verificação de regras, como também para um esforço mais substancial de garantia da qualidade nos projetos (NAWARI, 2012a).

Contudo, a simples aplicação de um software com diversas capacidades não se constitui em um método sistemático de verificação. É também necessário que exista um processo, ou seja, um conjunto de atividades, orientações e padrões que permita a verificação dos requisitos relevantes ao tipo de empreendimento a ser avaliado, em um contexto específico de aplicação. Apesar disso, a maioria dos trabalhos encontrados na literatura sobre verificação automatizada de requisitos é focada em problemas específicos, sem buscar compreender o processo como um todo (TAN; 
HAMMAD; FAZIO, 2010), tais como a verificação de sistemas prediais de água fria (MARTINS; MONTEIRO, 2012) e de sistemas de saída de incêndio (LEE et al., 2012; CHOI; CHOI; INHAN, 2014), ou a verificação de requisitos acústicos (PAUWELS et al., 2011). Outros estudos são focados em aspectos tecnológicos da verificação automatizada, tais como o melhoramento de padrões abertos compatíveis com a verificação de requisitos (PAUWELS et al., 2011; LEE et al., 2012), a criação de linguagens de consulta e de criação de regras (BORRMANN; RANK, 2010; NAWARI, 2012b) ou a parametrização de regras escritas de forma automática (SALAMA; EL-GOHARY, 2011; ZHANG; EL-GOHARY, 2013).

Percebe-se em algumas pesquisas anteriores sobre o assunto a ocorrência de interações entre soluções reais e propostas pelos pesquisadores (EASTMAN et al., 2009; LEE, 2011; SANGUINETTI et al., 2012), ou seja, algumas pesquisas propuseram soluções para ser efetivamente utilizadas pelos órgãos verificadores. Todavia, como consequência disso, verifica-se que essas experiências reais baseiam-se em soluções criadas especialmente para esse fim principalmente pelos próprios pesquisadores, o que dificulta a aplicação dos resultados desses estudos em outros contextos (YANG; XU, 2003; EASTMAN et al., 2009; LEE, 2011). Além disso, outro aspecto da implementação que não recebeu a devida atenção na literatura é a adaptabilidade das regras parametrizadas às definições normativas (YANG; XU, 2003; AEC3, 2013).

Assim, o objetivo deste trabalho consiste em propor um método de verificação automatizada de requisitos mínimos em empreendimentos de habitação de interesse social mediante a utilização de BIM. Esse método tem um caráter mais amplo que a simples aplicação de um software, contendo um conjunto de atividades, orientações e padrões estabelecidos a partir do contexto da habitação de interesse social no país. Pretende-se também compreender a natureza dos requisitos para esse tipo de empreendimento, analisar mudanças de processo decorrentes do uso de software para verificação automatizada de requisitos, assim como apontar dificuldades de realização dessa verificação. Deve-se destacar como delimitação deste trabalho o fato de que as verificações de códigos, leis e regras foram realizadas com a utilização de um software disponível no mercado, considerado como o mais avançado, sem alterações em seu código.

\section{Verificação automatizada}

Nesta seção faz-se uma diferenciação entre sistemas computacionais e métodos de verificação automatizada. Discute-se também o conteúdo dos guias de modelagem, os quais necessitam ser produzidos como referência para que a verificação automatizada seja padronizada, assim como o papel da interoperabilidade nesse processo.

\section{Sistemas computacionais e métodos de verificação automatizada}

Um sistema de verificação consiste em um software BIM que verifica de forma automatizada se o modelo do produto atende a uma série de regras que representam os requisitos a serem atendidos pela edificação. Por outro lado, o método de verificação inclui a aplicação do sistema assim como outras atividades complementares, mas inseparáveis do processo de verificação. Esse processo é denominado de uma forma geral na literatura de code checking (EASTMAN et al., 2009).

Em síntese, um sistema computacional de verificação automatizada processa uma grande quantidade de informações contida em uma base de dados, que contém um modelo BIM, e retorna um resultado para ser comparado com um valor predefinido (BORRMANN; RANK, 2010). Uma das principais dificuldades em fazer essa consulta está ligada ao fato de que objetos em um modelo BIM estão muitas vezes ligados uns aos outros através de uma rede de relacionamentos complexa (MAZAIRAC; BEETZ, 2012). Além dessa dificuldade, a verificação de requisitos exige da linguagem de consulta a capacidade de extrair informações de um modelo (BORRMANN; RANK, 2010).

Em complemento ao sistema computacional, os métodos de verificação envolvem mais atividades, uma vez que é necessário preparar os dados de entrada para que as análises sejam adequadas, assim como analisar os resultados para que estes sejam consistentes e úteis. Dessa forma, um método de verificação é formado pelo conjunto de procedimentos, classificações e ações necessárias à correta verificação automatizada. Diferentemente de um sistema computacional, que simplesmente aplica regras preestabelecidas a uma base de dados, os métodos de verificação devem ser estabelecidos considerando o contexto de avaliação no qual estão inseridos.

Nesse sentido, Eastman et al. (2009) afirmam que o processo de verificação automatizada pode ser dividido em quatro etapas: 
(a) interpretação e estruturação das regras;

(b) definição de parâmetros do modelo, com a criação de guias de modelagem e classificações de objetos;

(c) execução das regras; e

(d) análise de resultados.

Os mesmos autores afirmam que a etapa de execução da verificação (aplicação de software) pode ser dividida em dois estágios, conforme indica a Figura 1:

(a) a primeira deve ocorrer em um modelador BIM; e

(b) a segunda com o uso de uma ferramenta de verificação.

Além das etapas anteriormente citadas, Eastman et al. (2009) afirmam ser necessário preparar o modelo para que a aplicação da ferramenta ocorra satisfatoriamente, e isso ocorre de três maneiras:

(a) com a inserção das informações que precisam ser checadas no modelo;

(b) com a verificação da consistência dos modelos nos programas; $\mathrm{e}$

(c) com a classificação dos objetos do modelo, sendo que as duas últimas ocorrem dentro dos sistemas de verificação (EASTMAN et al., 2009).

A inserção das informações no software de modelagem BIM deve ser realizada com base em um guia de modelagem. Na aplicação do sistema de verificação, posteriormente, deve-se checar se todos os elementos necessários foram modelados e nomeados, e se os objetos estão conectados entre si de forma coerente (EASTMAN et al., 2009). Essa etapa é denominada verificação da consistência dos modelos.

Relacionando-se com a correta inserção de informações no modelo, a etapa de classificação poderia ser desnecessária caso os objetos do modelo fossem todos corretamente criados conforme um guia de modelagem consolidado. Contudo, com o objetivo de evitar verificações erradas, é possível a classificação manual dos objetos por parte dos verificadores. Dessa forma, busca-se evitar erros de nomenclatura inseridos nos modeladores BIM. Por exemplo, um lavatório pode ser nomeado "pia" e ter o tratamento de pia da cozinha quando da verificação. Evita-se também que a verificação deixe de ocorrer por terem sido utilizados diferentes nomes para um mesmo elemento - por exemplo, uma persiana pode ser denominada como "gelosia".

Nesse sentido, percebe-se ser necessário buscar um equilíbrio de forma que a automatização não acabe apenas transferindo o volume de trabalho dos verificadores para os projetistas. Segundo Eastman et al. (2009), a implementação da verificação automatizada envolve muitos trades-off $s^{2}$ entre o trabalho de documentação para os projetistas e a capacidade de inferência dos programas de verificação. Ou seja, é necessário um processo mais complexo de modelagem para que o modelo BIM seja adequado, tornando a verificação automatizada mais eficaz.

\section{Figura 1 - Fluxo de atividades envolvidas na verificação automatizada}

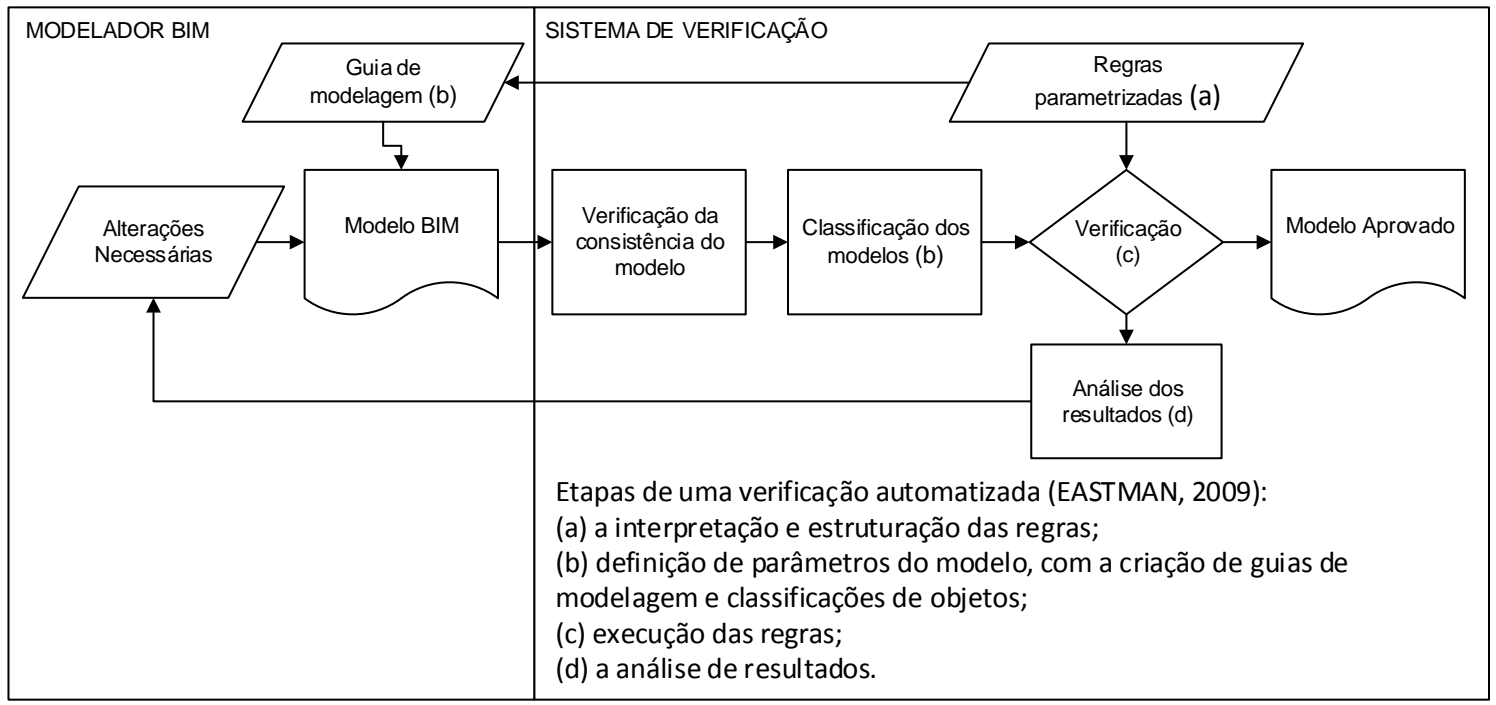

${ }^{2}$ Trade-offs são escolhas realizadas durante a tomada de decisão. A partir desse tipo de escolha, geralmente se perde uma qualidade ou aspecto de algo, mas se ganha, em troca, outra qualidade ou aspecto.

262 Fernandes, G. von der H.; Formoso, C. T.; Tzortzopoulos-Fazenda, P. 


\section{Guias de modelagem e nomenclatura}

Para o desenvolvimento de modelos BIM, é crucial definir tanto o objetivo quanto o nível de desenvolvimento da modelagem para o propósito a ser atendido (LEITE et al., 2011). Existem diversos guias de modelagem em diversos países cujo objetivo é, em geral, a inserção das informações necessárias nos modelos, dependendo de suas aplicações, tanto em relação aos objetos modelados quanto da denominação deles corretamente (EASTMAN et al., 2011; SHIGAKI; TZORTZOPOULOS, 2013).

No caso da verificação automatizada, os guias de modelagem e a nomenclatura têm grande importância devido à necessidade de geração de informações que possam ser testadas (NAWARI, 2012a; EASTMAN et al., 2009). Tais definições são necessárias porque a imprecisão e a ambiguidade são características essenciais da comunicação humana, o que pode dificultar a descrição de objetos para posterior utilização em sistemas de verificação (SAUSSURE, 2004).

Nesse sentido, dentro do IFC são disponibilizados grupos de propriedades chamados de property sets (PSET). Eles são os mais utilizados e necessários para os usuários, mas é possível definir outros, de forma a adaptar o modelo a determinada necessidade (WIX; KARLSHOJ, 2007). Assim, os guias de modelagem especificam os grupos de propriedades que são necessários e as informações que estes devem conter para uma verificação automatizada satisfatória (PAUWELS et al., 2011).

\section{Interoperabilidade}

Todas as experiências bem-sucedidas de sistemas computacionais de verificação automatizada enfatizam a necessidade de interoperabilidade em seus guias de modelagem (EASTMAN et al., 2011). De fato, a utilização de um sistema proprietário e fechado para a verificação automatizada traz uma série de dificuldades:

(a) necessidade de atualização da versão dos programas computacionais;

(b) futuro acesso a informações gravadas em formatos privados;

(c) responsabilidade por erros em traduções e por mecanismos para testes; $\mathrm{e}$

(d) certificações (LAAKSO; KIVINIEMI, 2012).

Assim, a utilização de arquivos abertos no formato IFC é muito importante para a verificação automatizada no âmbito de organismos governamentais envolvidos na avaliação de projetos propostos por diferentes empresas ou profissionais.

Entretanto, a utilização do formato IFCnormalmente apresenta limitações quanto à compreensão dos resultados da verificação. É necessário criar um relatório com os itens não conformes a serem informados aos projetistas pelo fato de que o formato IFC não contém a forma como as geometrias foram geradas e por isso não viabiliza o retorno aos modelos com códigos proprietários das informações analisadas (WIX; KARLSHOJ, 2007). A Figura 2 é uma síntese do fluxo de atividades apresentado na Figura 1, com foco na conversão de informações entre relatórios, considerando o modelo BIM e o arquivo IFC.

\section{Método de pesquisa}

No presente estudo foi adotada a abordagem metodológica denominada Design Science Research (VAN AKEN, 2004). Lukka (2003) define essa abordagem, também denominada de Constructive Research, como um processo de pesquisa para produção de soluções inovadoras para classes de problemas enfrentados no mundo real, contribuindo também para a construção de teorias nas disciplinas em que é aplicada.

Figura 2 - Síntese do fluxo de atividades envolvidas na verificação com o uso de IFC

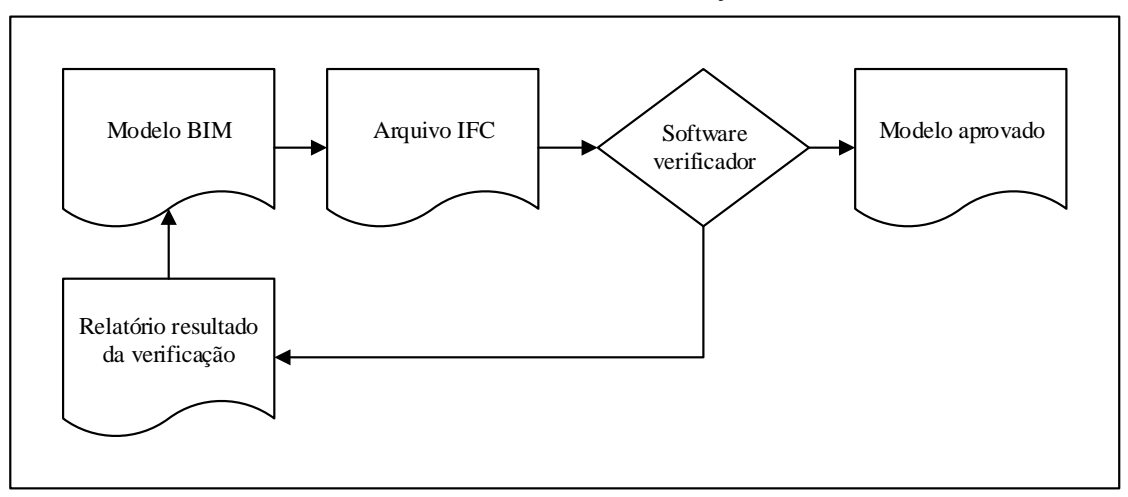


Esta pesquisa foi dividida em cinco fases, conforme a Figura 3:

(a) revisão de literatura, desenvolvida ao longo de todo o período;

(b) etapa de compreensão do problema real;

(c) etapa de construção do artefato;

(d) etapa de implementação e refinamento; e

(e) etapa de análise e reflexão.

Essas etapas relacionam-se com as etapas da Design Science Research sugeridas por Kasanen, Lukka e Siitonen (1993), conforme ilustrado na parte superior da mesma figura.

Uma característica importante do tema desta pesquisa é a velocidade com que se desenvolvem as soluções digitais. Conforme March e Smith (1995), os artefatos desenvolvidos em pesquisas de TI são perecíveis, sendo necessário, por essa razão, produzir artefatos em um ritmo nunca visto antes. Além disso, em Design Science Research o objeto de pesquisa é mutandum (VAN STRIEN, 1997), ou seja, nessa área do conhecimento não deve haver muita preocupação com o que é, mas com o que poderá ser (VAN AKEN, 2004).

\section{Etapa de compreensão}

$\mathrm{Na}$ etapa de compreensão da pesquisa buscou-se entender o contexto de aplicação do método de verificação. Com esse objetivo foi realizada pesquisa bibliográfica específica sobre a verificação automatizada de projetos e, em um segundo momento, estudos referentes à análise de projetos por órgãos verificadores, em especial de habitação de interesse social e de programas habitacionais operacionalizados pela Caixa.

Após um entendimento inicial das características do programa MCMV, optou-se por delimitar o estudo empírico à faixa 1 desse programa, referente a famílias com renda de até três salários mínimos. Essa modalidade foi escolhida por sua relevância social, pela elevada parcela que representa no programa MCMV e também pelo fato de a Caixa, como representante dos fundos de recursos desse programa, ter maior possibilidade de interferência nos projetos.

Quanto à escolha do sistema de verificação, a revisão de literatura indicou que o softwareSolibri Model Checker (SMC) tem sido o mais utilizado, tanto em pesquisas acadêmicas como em sistemas de verificação desenvolvidos em iniciativas governamentais (EASTMAN et al., 2009; LEE et al., 2012; LEE, 2011; SANGUINETTI et al., 2012). Foram considerados outros pacotes computacionais disponíveis no mercado, tais como o dRufus e o Autodesk Naviswork. Entretanto, optou-se por utilizar o software SMC, uma vez que este possui uma biblioteca consistente de regras predefinidas e existe a possibilidade de alterar essas regras sem a necessidade de programação. Além disso, o SMC permite fácil visualização dos modelos.

\section{Figura 3 - Delineamento da pesquisa}

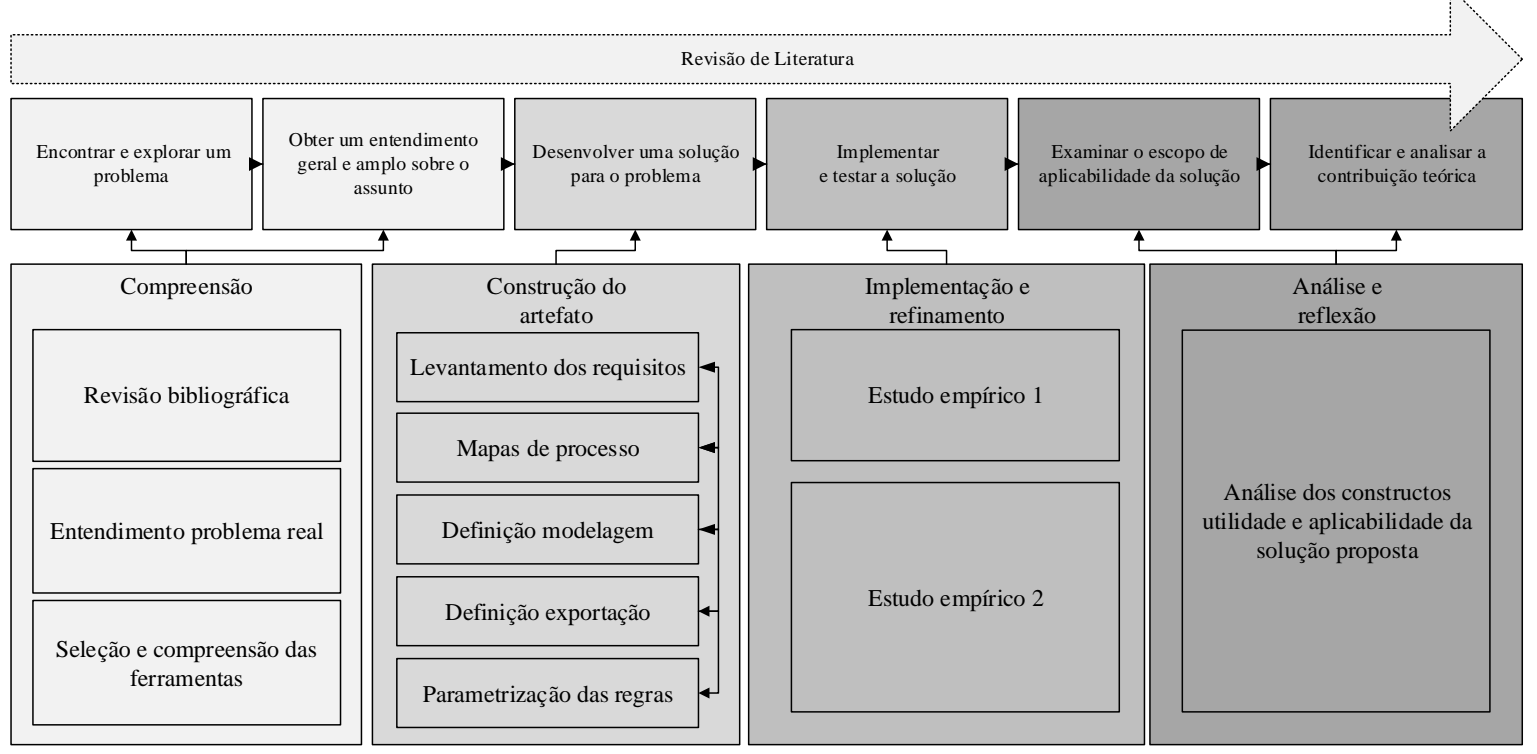

264 Fernandes, G. von der H.; Formoso, C. T.; Tzortzopoulos-Fazenda, P. 


\section{Etapa de construção do artefato}

A etapa de construção do artefato foi dividida nas seguintes atividades:

(a) levantamento dos requisitos;

(b) mapeamento de processos;

(c) definição da modelagem;

(d) definição dos parâmetros de exportação; e

(e) parametrização das regras no software escolhido.

Embora essa etapa tenha envolvido atividades distintas, ela teve um caráter iterativo, existindo sobreposição entre tais atividades.

Primeiramente, foram identificadas as especificações que serviram de base para as verificações. Este trabalho considerou apenas os requisitos normativos e explicitados nas especificações mínimas do Ministério das Cidades (BRASIL, 2013). Tais planilhas fazem parte do Anexo I da Portaria n ${ }^{\circ} 168$, de 12 de abril de 2013 (BRASIL, 2013). Dessas especificações mínimas foram selecionadas apenas as que dizem respeito à unidade habitacional, uma vez que a verificação dos requisitos referentes ao empreendimento como um todo demandaria recursos e tempo não disponíveis para este trabalho. Os itens do Anexo I selecionados foram então separados em regras individuais.Por exemplo, esse anexo tem redação para o mobiliário mínimo do quarto de casal conforme o Quadro 1, abaixo. Desse item foram extraídas cinco regras, que verificam cada um dos objetos exigidos.

Assim, como resultado desse processo, foram listadas 45 regras divididas em cinco categorias:

(a) quantidade mínima de móveis;

(b) circulação mínima;

(c) dimensões mínimas;

(d) portas; e

(e) janelas, acabamentos e materiais.

Uma definição importante do método é o momento em que ocorre a verificação e quando os benefícios de sua aplicação podem ser mais evidentes, sendo isso alcançado com o mapeamento do processo de análise de projetos. Baseado no método desenvolvido pela Building Smart, mais especificadamente o trabalho de Wix e Karlshoj (2007), foram mapeados três processos utilizando a notação para uma modelagem de processos de negócio, BPMN (Business Process Modeling Notation). De acordo com esse método, toda a vez que é gerado um documento e existe uma troca, esta gera uma série de requisitos de intercâmbio, chamados de exchange requirements (ER) (WIX; KARLSHOJ, 2007).

Seguindo a identificação dos objetos necessários para a verificação, e com base nos mapas de processo e nos requisitos levantados, foram identificados os requisitos de intercâmbio nos mapas de processo do Information Delivery Manual (IDM). Estes, por sua vez, dão forma ao Model View Definition (MVD) para a troca de dados entre projetistas e verificadores dentro do método da Building Smart (WIX; KARLSHOJ, 2007). Contudo, um MVD, para ser assim chamado, teria de ser certificado por esse consórcio de empresas. Por esse motivo, foram criadas apenas definições de exportação no software modelador.

A elaboração das regras no SMC é limitada a uma lista predefinida de regras. Por exemplo, a regra referente à inclinação de rampas verifica o comprimento máximo da rampa, e não o desnível máximo, como indica a NBR 9050 (ABNT, 2004). Nesse caso, quando da definição das regras no sistema, cabe ao desenvolvedor fazer essa conversão (ver exemplo da Figura 4). Com o objetivo de buscar a maior aderência possível das regras do sistema às especificações mínimas do MCMV, diversas dúvidas sobre a configuração de algumas dessas regras foram enviadas para a empresa que desenvolveu o SMCe respondidas por seu representante para as Américas.

\section{Etapa de implementação e refinamento}

A etapa de implementação e refinamento iniciouse com a seleção de dois empreendimentos para testar o método proposto, sendo consideradas sugestões de profissionais da Gerência Executiva de Habitação (Gihab) da Caixa de Porto Alegre. Buscaram-se dois projetos distintos, principalmente quanto à tipologia e à forma de provisão, conforme indica o Quadro 2, abaixo.

Quadro 1 - Especificações mínimas do programa MCMV referentes ao mobiliário do quarto de casal

\begin{tabular}{|c|c|c|}
\hline Item & Ambiente & \multicolumn{1}{c|}{ Especificação mínima } \\
\hline 1.1 & Dormitório casal & $\begin{array}{l}\text { Quantidade mínima de móveis: 1 cama }(1,40 \mathrm{~m} \times 1,90 \mathrm{~m}) ; 1 \text { criado-mudo } \\
(0,50 \mathrm{~m} \text { x 0,50 m); e 1 guarda-roupa }(1,60 \mathrm{~m} \times 0,50 \mathrm{~m}), 2 \text { tomadas }\end{array}$ \\
\hline
\end{tabular}


Figura 4 - Regra contendo parâmetros para a verificação de rampas no SMC

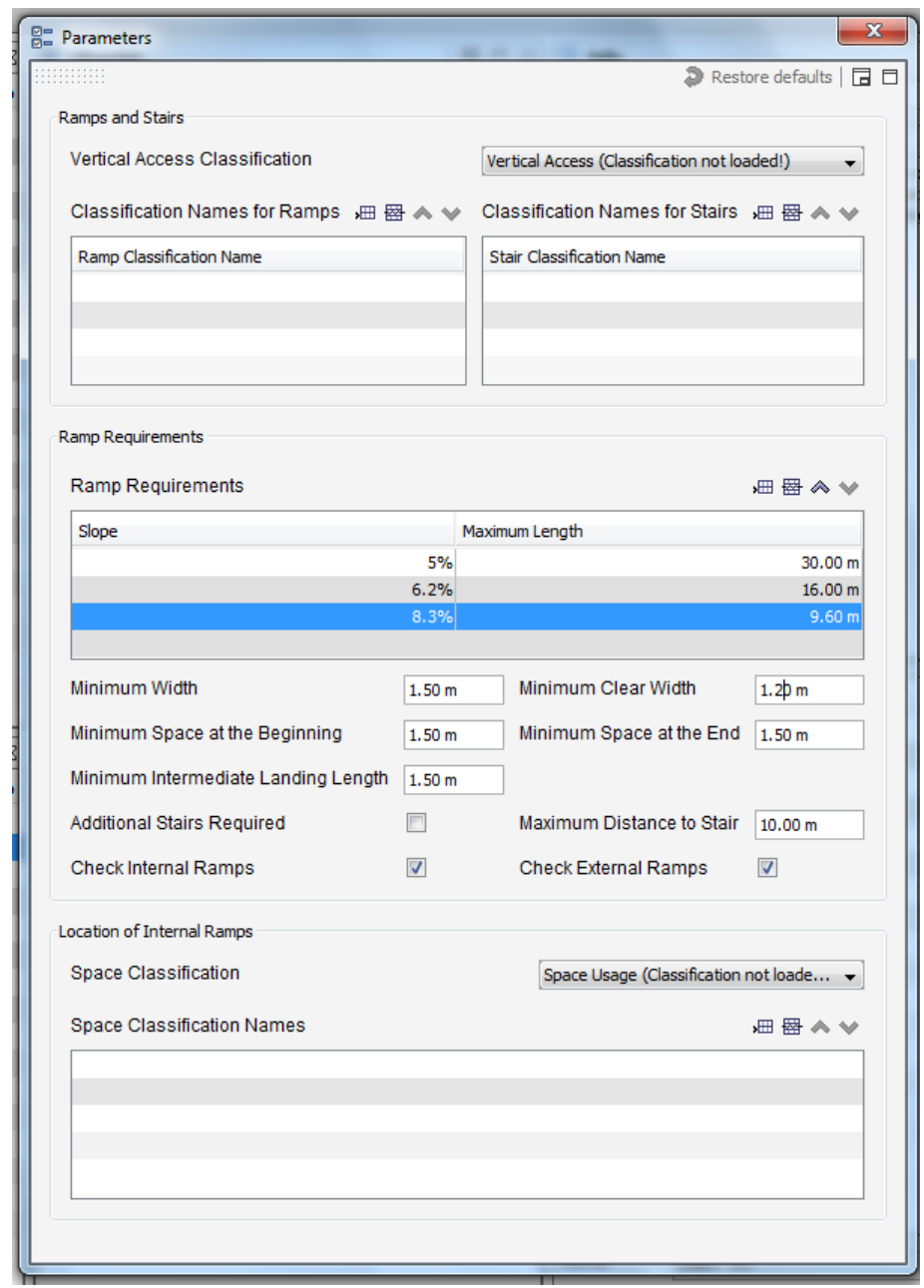

Quadro 2 - Diferenças entre empreendimentos dos estudos empíricos 1 e 2

\begin{tabular}{|l|l|l|}
\hline \multicolumn{1}{|c|}{ Característica } & \multicolumn{1}{c|}{ Empreendimento 1 } & \multicolumn{1}{c|}{ Empreendimento 2 } \\
\hline Proponente & Empresa & Cooperativa \\
\hline Fonte de recursos & $\begin{array}{l}\text { FAR - Fundo de Arrendamento } \\
\text { Residencial }\end{array}$ & $\begin{array}{l}\text { FDS - Fundo de } \\
\text { Desenvolvimento Social }\end{array}$ \\
\hline Profissional responsável pelo projeto & Arquiteto e urbanista & Engenheiro civil \\
\hline Tipologia & Edifício de cinco pavimentos & Casas sobrepostas \\
\hline Área interna das unidades & $39 \mathrm{~m}^{2}$ & $42 \mathrm{~m}^{2}$ \\
\hline
\end{tabular}

O método proposto foi então aplicado nos dois empreendimentos e comparado com o processo manual realizado por técnicos da Caixa, ou seja, os técnicos fizeram a verificação inicial do empreendimento conforme as práticas correntes e identificaram as pendências referentes à unidade habitacional. Ao mesmo tempo, os projetos foram modelados pelo primeiro autor deste trabalho em BIM, e a verificação foi realizada de forma automatizada.

\section{Etapa de análise e reflexão}

A avaliação do artefato, segundo March e Smith (1995), possibilita verificar o progresso alcançado e sua funcionalidade. Foram definidos dois critérios para a avaliação do sistema de verificação automatizada: utilidade da solução e aplicabilidade.

O critério de avaliação utilidade da solução está relacionado à contribuição do método proposto para a verificação dos requisitos de empreendimentos habitacionais de interesse social.

266 Fernandes, G. von der H.; Formoso, C. T.; Tzortzopoulos-Fazenda, P. 
Como forma de avaliar a utilidade do método de verificação, foram considerados os seguintes critérios secundários:

(a) padronização: refere-se à padronização do processo de verificação das propostas;

(b) visualização: refere-se à visualização das regras visando a sua organização; e

(c) detecção de problemas: refere-se à abrangência e precisão do método de verificação na detecção de problemas no projeto.

$\mathrm{Na}$ avaliação da utilidade foram considerados os resultados das verificações, ou seja, as informações que o sistema retorna da verificação ainda na tela do computador, e os relatórios de verificação, que são essas mesmas informações organizadas em formato de texto com imagens para repassar aos projetistas.

Já o critério de avaliação aplicabilidade da solução refere-se à viabilidade de sua implementação. Esse critério foi desdobrado em outros três critérios secundários, apresentados a seguir:

(a) automatização: relacionada à eliminação de etapas, tais como transferência de informações ou ciclos iterativos;

(b) velocidade: esta análise é baseada na comparação entre os tempos dos dois métodos de análise, manual e automatizado; e

(c) adaptabilidade: refere-se à possibilidade de inserção do sistema dentro dos processos internos do agente financeiro, que neste estudo foi a Caixa.

Para avaliação do critério aplicabilidade foram consideradas as seguintes fontes de evidências: mapas de processo de verificação, entrevistas com participantes e comparação entre resultados das verificações. O Quadro 3, abaixo, sintetiza os critérios e indica as fontes de evidência utilizadas na análise.

Ao final de cada estudo, empírico, foi realizada uma reunião com cada um dos profissionais responsáveis pela verificação, sendo feita uma comparação entre os resultados encontrados pela verificação automatizada e aqueles produzidos pela verificação manual. Nessas reuniões os técnicos apresentaram os problemas identificados na verificação manual, ao mesmo tempo em que foram apresentadas as inconsistências apontadas pela verificação automatizada. Buscou-se também obter a percepção dos envolvidos sobre a adaptabilidade do método ao processo atual de verificação de projetos.

\section{Resultados}

\section{Produção e análise de projetos de Habitação de Interesse Social}

Como resultado do método proposto, foram mapeados três cenários do processo de análise da Caixa utilizando a notação BPMN. Partindo do cenário atual e sem a utilização da verificação automatizada, o primeiro mapa de processo mostra a situação existente de troca de informações entre projetistas e analistas; no segundo, a situação imaginada com o emprego da verificação automatizada realizada pelos técnicos da Caixa; e, finalmente, no terceiro, a verificação é realizada pelo coordenador de projetos, e o modelo é enviado à Caixa para conferência de itens não verificados automaticamente, cenário no qual o nível de automação é mais elevado.

O foco desse mapeamento foi identificar de que forma o processo de verificação ocorre com o menor número de retrabalhos e etapas. Assim, a quantidade de impressões registradas na raia de documentos dos mapas indica a necessidade de atividades de inserção manual de informações, representando oportunidades para tornar o processo mais digital. Contudo, é sabido que a redução do número de impressões por si só não é o objetivo da implementação da verificação automatizada, mas, sim, os ganhos advindos da execução do processo da forma mais automatizada possível.

\section{Quadro 3 - Critérios e fontes de evidências utilizadas na avaliação final}

\begin{tabular}{|l|l|l|}
\hline \multicolumn{1}{|c|}{ Critérios } & Critérios secundários & \multicolumn{1}{c|}{ Fontes de evidência } \\
\hline Utilidade & Padronização & Resultados das verificações \\
\hline & Visualização & Relatórios de verificação \\
\hline & Detecção de problemas & Resultados das verificações \\
\hline Aplicabilidade & Automatização & Mapas do processo de verificação \\
\hline & Velocidade & Prazo de análise \\
\hline & Adaptabilidade & $\begin{array}{l}\text { Mapas do processo de verificação e entrevistas } \\
\text { semiestruturadas com participantes }\end{array}$ \\
\hline
\end{tabular}


No mapa do processo atual (Figura 5), o BIM é utilizado apenas para modelagem e posterior impressão, ou seja, os projetos são todos apresentados impressos para análise da Caixa depois de terem sido modelados digitalmente pelos projetistas. O mapa demonstra que devem ser produzidos ao menos quatro documentos impressos. Isso ocorre toda a vez que o projeto é submetido para verificação e quando se geram relatórios. Ao mesmo tempo, apenas três trocas ocorrem digitalmente, somente quando acontece entre os projetistas de uma mesma equipe.

$\mathrm{Na}$ segunda situação (Figura 6), os projetistas seguem desenvolvendo em BIM os projetos, cabendo à Caixa realizar a avaliação pelo sistema de verificação automatizada. Em função dessa mudança, o número de documentos impressos diminui para dois, ao passo que aumentam as trocas por meio digital. Nesse caso, a existência dos documentos físicos deve-se à necessidade de gerar relatórios a partir das verificações apenas. $\mathrm{Ou}$ seja, todas as trocas de informação que envolvem projetos podem ocorrer por meio de modelos digitais.

A situação mais avançada no sentido da automatização do processo e da redução de trocas impressas ocorre quando a própria equipe de projeto realiza as verificações automatizadas (Figura 7). Assim, apenas no momento da verificação dos itens faltantes são gerados documentos impressos para que sejam feitas as alterações nos modelos. Dessa forma, considerando que o próprio projetista faz as verificações, estas podem ocorrer a qualquer momento e sempre que o profissional entender necessário. Percebe-se nessa situação ganhos efetivos de produtividade e redução de retrabalhos, uma vez que as decisões de projeto podem ser testadas e ajustadas tão logo sejam tomadas pelos projetistas, em vez de ter que aguardar a avaliação do projeto como um todo.

Além disso, a necessidade de submissão digital dos projetos não somente amplia o interesse dos usuários a respeito da tecnologia, como também torna seu uso mais avançado do que o experimentado pela maioria dos usuários que já utilizam BIM. O fato de os próprios profissionais realizarem a checagem pode ampliar o escopo de uso do sistema e ajudar os projetistas em outras verificações.

Figura 5 - Fluxo da análise de projetos utilizando BIM

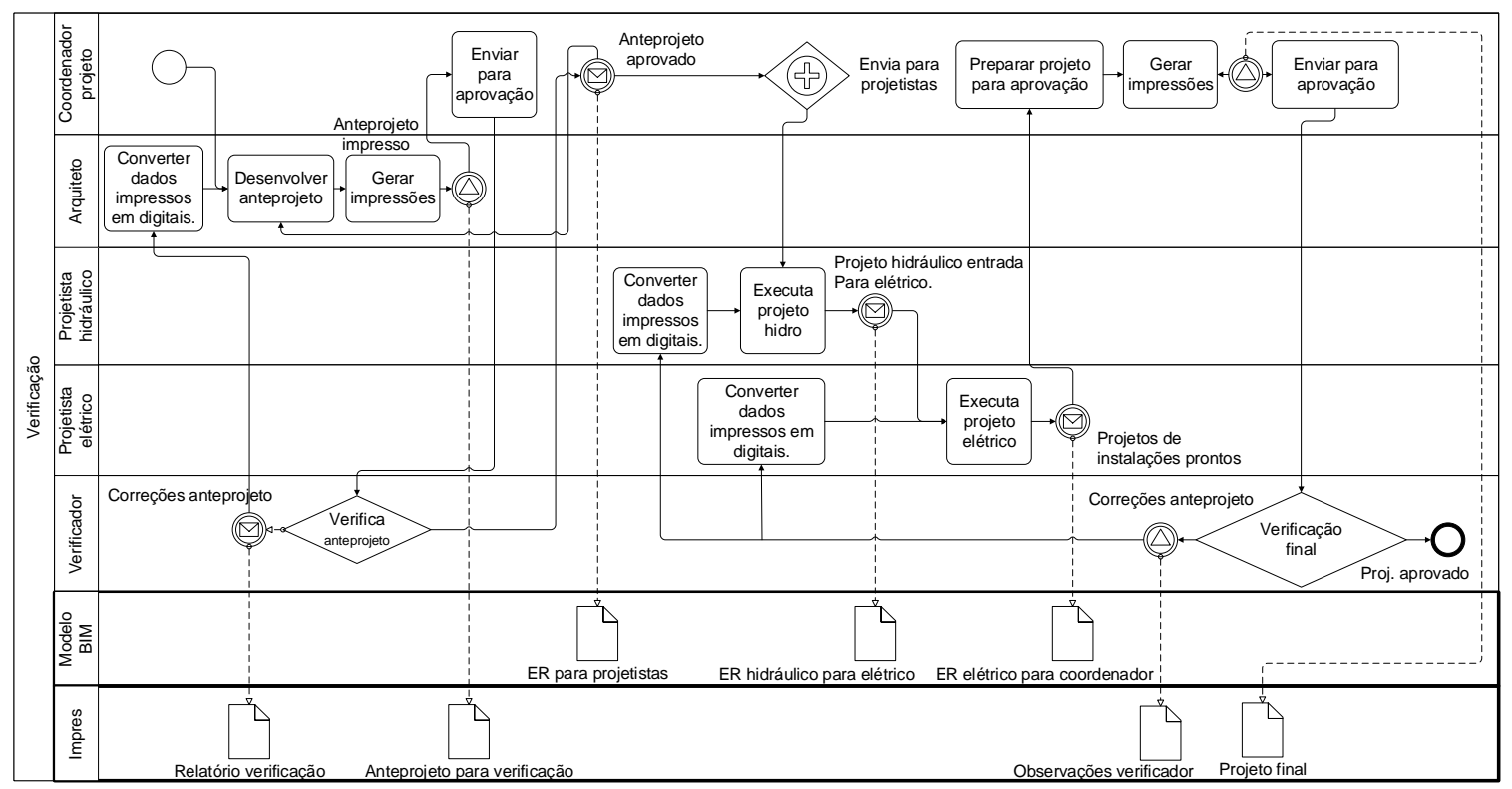

268 Fernandes, G. von der H.; Formoso, C. T.; Tzortzopoulos-Fazenda, P. 
Figura 6 - Fluxo com a verificação sendo realizada pelos técnicos da Caixa

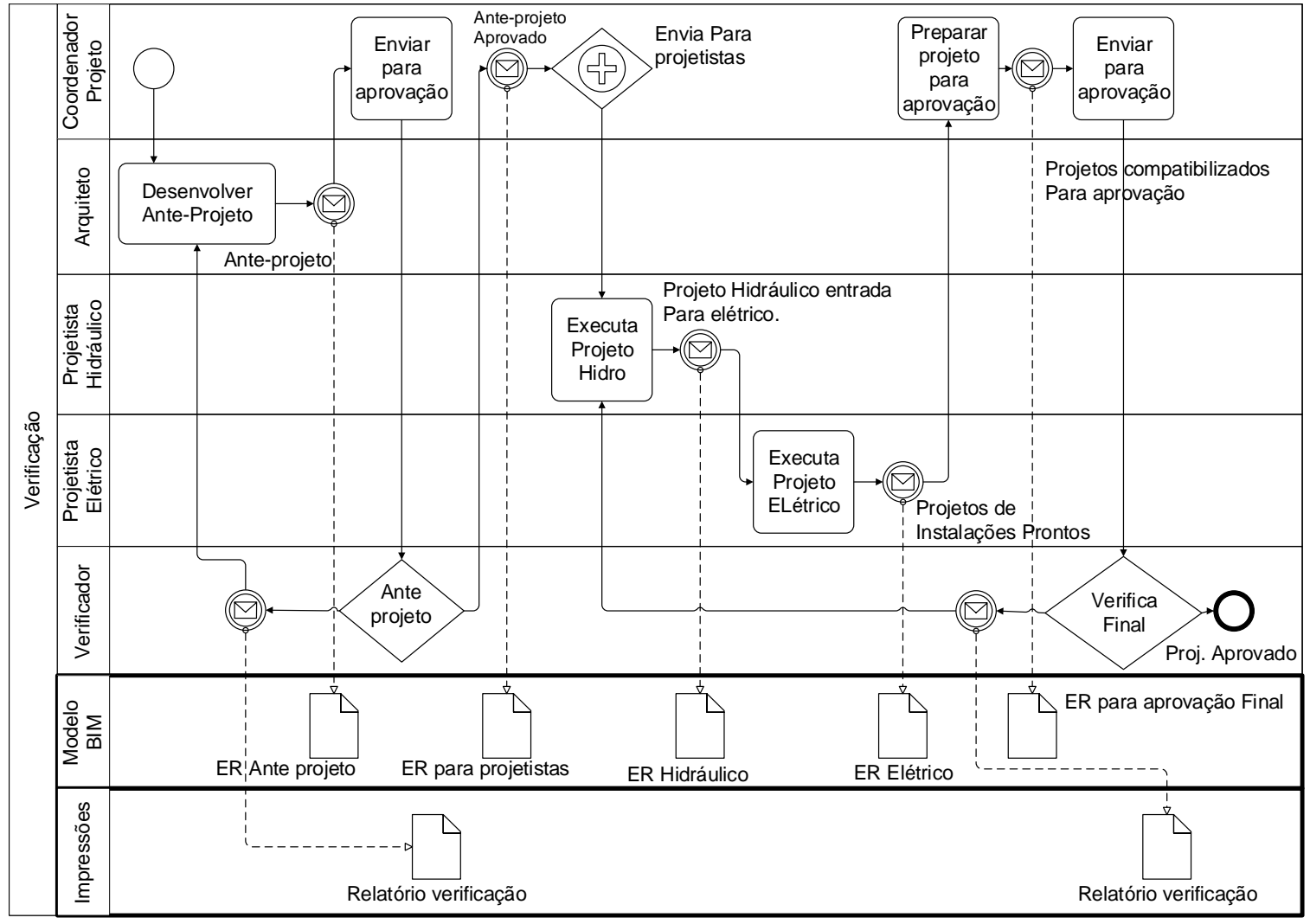

Figura 7 - Fluxo da análise de projetos com a verificação sendo realizada pelos projetistas

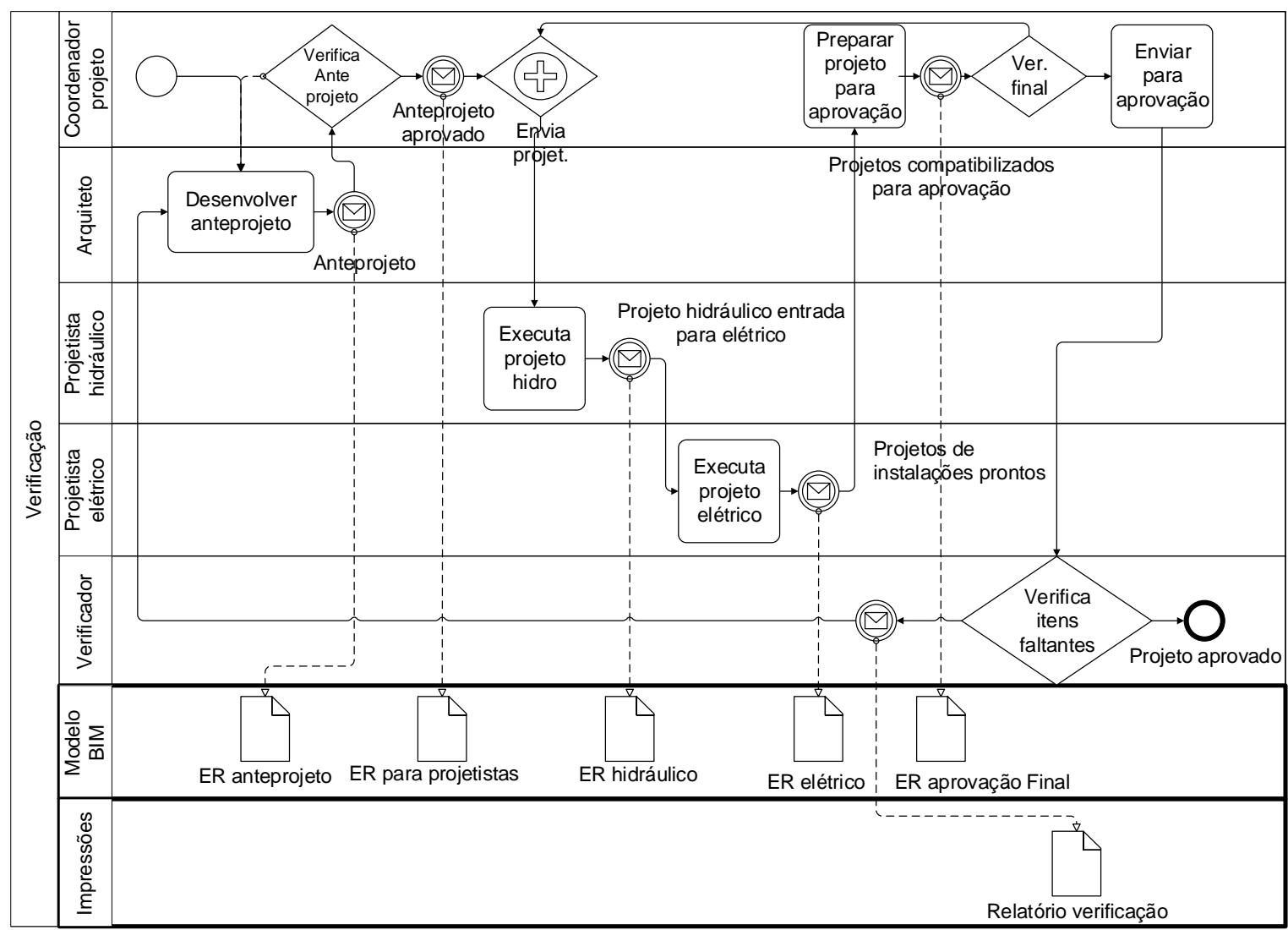




\section{Escopo do sistema de verificação automatizada}

Com o objetivo de criar as regras no SMC, as 45 regras derivadas das especificações mínimas identificadas anteriormente foram refinadas e, ao final, geraram 49 verificações no SMC. Em parte, o número maior de regras no SMC deve-se à criação de regras que verificam a confiabilidade do modelo. Estas foram então categorizadas como segue:
(a) confiabilidade do modelo;
(b) mobiliário mínimo;
(c) distâncias mínimas;
(d) giro;
(e) largura de ambientes;
(f) área total;
(g) pé-direito;
(h) altura de tomadas;
(i) portas;
(j) janelas; e
(k) materiais.

A confiabilidade do modelo é testada por três regras que verificam se todos os objetos possuem as dimensões de largura e comprimento especificadas e se os espaços encostam ou ultrapassam tetos ou forros. A verificação do mobiliário mínimo é feita em relação às dimensões mínimas de todos os móveis e equipamentos necessários no modelo.

Em seguida, é feita a verificação das distâncias e dimensões mínimas necessárias nos móveis e equipamentos sanitários. Outro conjunto de regras verifica se a unidade de giro de uma cadeira de rodas tem condições de ser colocada dentro de cada ambiente. Ainda dentro do contexto de medições do modelo, é verificada a largura mínima dos ambientes e a área total da unidade. A verificação das alturas de pé-direito e das tomadas é feita em outros dois conjuntos de regras. Além dessas verificações, são reservados dois grupos de regras para verificar exclusivamente as portas e janelas da edificação. Por fim, é feita a verificação dos materiais aplicados - esta tem um caráter totalmente semântico e depende da correta denominação dos objetos conforme o guia de modelagem.

Das regras levantadas nas especificações mínimas, 13 não puderam ser verificadas de forma automatizada pelo SMC em sua totalidade, ou seja aproximadamente $28 \%$ das 45 regras (Quadro 4). Essa dificuldade deve-se a:
(a) inexistência de regras no programa verificador;

(b) limitações da modelagem BIM em situações nas quais a inserção de informações nos modelos não se justifica;

(c) existência de requisitos muito abertos e ambíguos; e

(d) casos de itens parcialmente verificáveis.

Houve dois casos de requisitos muito abertos ou ambíguos que não puderam dar origem a regras de verificação automatizada. Por sua natureza, ambos os requisitos poderiam ser refinados para permitir uma avaliação objetiva das dimensões necessárias.Ou seja, a imprecisão de algumas especificações mínimas pode prejudicar o processo de verificação por causar ambiguidades, embora se possa admitir que alguns requisitos sejam de difícil quantificação e necessitam de uma avaliação de caráter subjetivo.

Houve seis casos de itens parcialmente verificáveis, relacionados com limitações do softwareverificador, já que os requisitos não puderam ser adaptados às regras existentes. Entre eles se destacam:

(a) a verificação do espaço de giro é retangular no sistema e tem uma das faces arredondadas nas especificações mínimas; e

(b) as janelas são verificadas por porcentagem da área do ambiente nos requisitos mínimos, enquanto um número absoluto é necessário no sistema.

Enfim, o processo de construção do sistema foi bastante iterativo, com muitos ciclos de tentativa e erro. Para tanto, todas as regras parametrizadas foram testadas em um modelo semelhante aos projetos apresentados para análise na Caixa. O modelo dessa unidade habitacional foi alterado conforme a necessidade de testar determinada especificação mínima, conforme relatado anteriormente. 
Quadro 4 - Lista de especificações mínimas que não podem ser verificadas pelo SMC

\begin{tabular}{|c|c|c|c|c|c|c|}
\hline & Classificação & Regra & 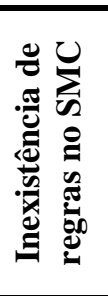 & 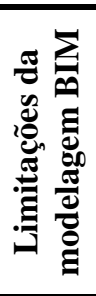 & 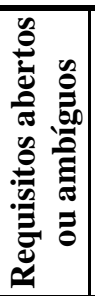 & 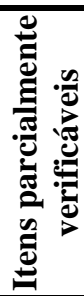 \\
\hline 2 & $\begin{array}{l}\text { Quantidade mínima de } \\
\text { móveis }\end{array}$ & & & & & \\
\hline 2.4 & Cozinha & Previsão para armário sob a pia e gabinete & & & $\mathrm{x}$ & \\
\hline 2.7 & Banheiro & Vaso com caixa de descarga acoplada & & & & $\mathrm{X}$ \\
\hline 3 & Circulação mínima & & & & & \\
\hline 3.3 & Banheiro & $\begin{array}{l}\text { Assegurar a área para transferência ao vaso } \\
\text { sanitário e ao box }\end{array}$ & & & $\mathrm{x}$ & \\
\hline 3.4 & Em todos os cômodos & $\begin{array}{l}\text { Deve ser possível inscrever em todos os } \\
\text { cômodos o módulo de manobra de } 180^{\circ} \text { da } \\
\text { NBR } 9050(1,20 \mathrm{~m} \mathrm{x} 1,50 \mathrm{~m})\end{array}$ & & & & $\mathrm{X}$ \\
\hline 4 & Dimensões mínimas & & & & & \\
\hline 4.7 & Em toda a unidade & Desnível máximo de $15 \mathrm{~mm}$ & $\mathrm{x}$ & & & \\
\hline 5 & Portas & & & & & \\
\hline 5.2 & Todas as portas & Alavanca a $1 \mathrm{~m}$ do piso & & $\mathrm{x}$ & & \\
\hline 5.4 & Todas as portas & $\begin{array}{l}\text { Área de aproximação de } 0,60 \mathrm{~m} \text { interno e de } \\
0,30 \mathrm{~m} \text { externo }\end{array}$ & $\mathrm{x}$ & & & \\
\hline 6 & Janelas & & & & & \\
\hline 6.1 & Quartos & $1,50 \mathrm{~m}^{2}-5 \%$ & $\mathrm{x}$ & & & \\
\hline 6.2 & Sala de estar/refeições & $2,00 \mathrm{~m}^{2}-5 \%$ & $\mathrm{x}$ & & & \\
\hline 7 & $\begin{array}{l}\text { Acabamentos e } \\
\text { materiais }\end{array}$ & & & & & \\
\hline 7.11 & Batentes & Em aço ou madeira & $\mathrm{x}$ & & & \\
\hline 7.12 & Batentes & Que possibilite a inversão do sentido & & $\mathrm{X}$ & & \\
\hline 7.13 & Torneiras & Metálicas com alavanca ou cruzeta & & & & $\mathrm{X}$ \\
\hline 7.14 & $\begin{array}{l}\text { Acabamento do } \\
\text { registro }\end{array}$ & Alavanca ou cruzeta & & & & $\mathrm{x}$ \\
\hline
\end{tabular}

\section{Versão final do método}

A Figura 8 apresenta o fluxo proposto para o método de verificação. O método, em sua versão final, tem como núcleo central as definições de modelagem BIM, os parâmetros de exportação dos modelos criados e as regras parametrizadas em um programa verificador. $\mathrm{O}$ desenvolvimento do método tomou como referência as etapas propostas por Eastman et al. (2009), apresentadas na Figura 1. Contudo, tendo em vista a aplicação real proposta neste estudo, foram feitas adaptações em função da utilização do formato IFC para a troca de arquivos. Assim, como apresentado na Figura 2, na versão final do método também é necessário gerar relatórios da verificação para que o modelo a ser verificado seja alterado. Como a classificação dos objetos é uma das capacidades do software de verificação, esta é realizada nele próprio, e não em uma ferramenta isolada, como sugerem Choi, Choi e Inhan (2014).
O processo de verificação deve iniciar-se com a correta elaboração do modelo e sua exportação em IFC conforme orientações do guia de modelagem. Uma vez em IFC, o modelo é importado no sistema de verificação, classificado, checado e aprovado. Ao mesmo tempo, as regras em forma de texto geram as verificações parametrizadas no sistema de verificação, e, a partir destas, são identificadas as necessidades de modelagem que compõem o guia de modelagem.

\section{Estudo empírico 1}

Os profissionais encarregados de avaliação de projetos na Caixa indicaram que as áreas molhadas dos apartamentos constituíram-se em pontos críticos da análise. Isso se deve ao fato de que estes são os menores espaços de uma habitação, podendo haver dificuldades de acessibilidade por parte de deficientes físicos. De fato, os itens não conformes em relação ao atendimento aos 
requisitos foram todos encontrados nesses dois espaços. Nesse sentido, tanto a verificação automatizada quanto a manual apontaram problemas na acessibilidade no banheiro. Esta ficou prejudicada pela abertura da porta, que não respeita a distância mínima de um 1,20 m em ambos os lados. A Figura 9 ilustra essa situação.
Ambas as verificações também identificaram que o espaço para a cozinha era inferior ao exigido pelo programa, conforme ilustrado pela Figura 10. Contudo, o profissional responsável pela análise apontou que o mobiliário da cozinha estava dimensionado com folga e que, com as dimensões mínimas, seriam atendidas as exigências do programa.

Figura 8 - Fluxo do método proposto de verificação automatizada

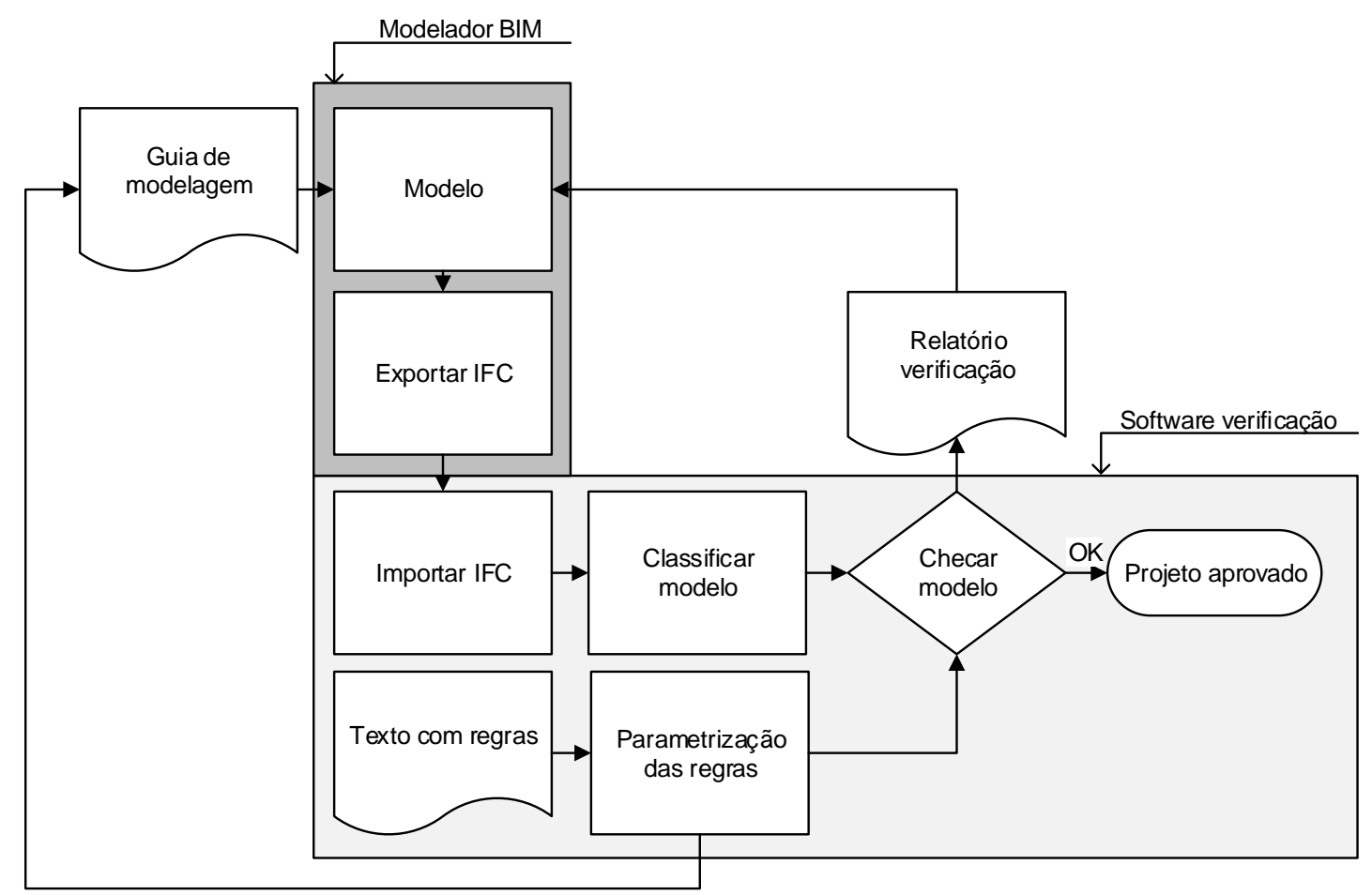

Figura 9 - Área em frente à porta no banheiro

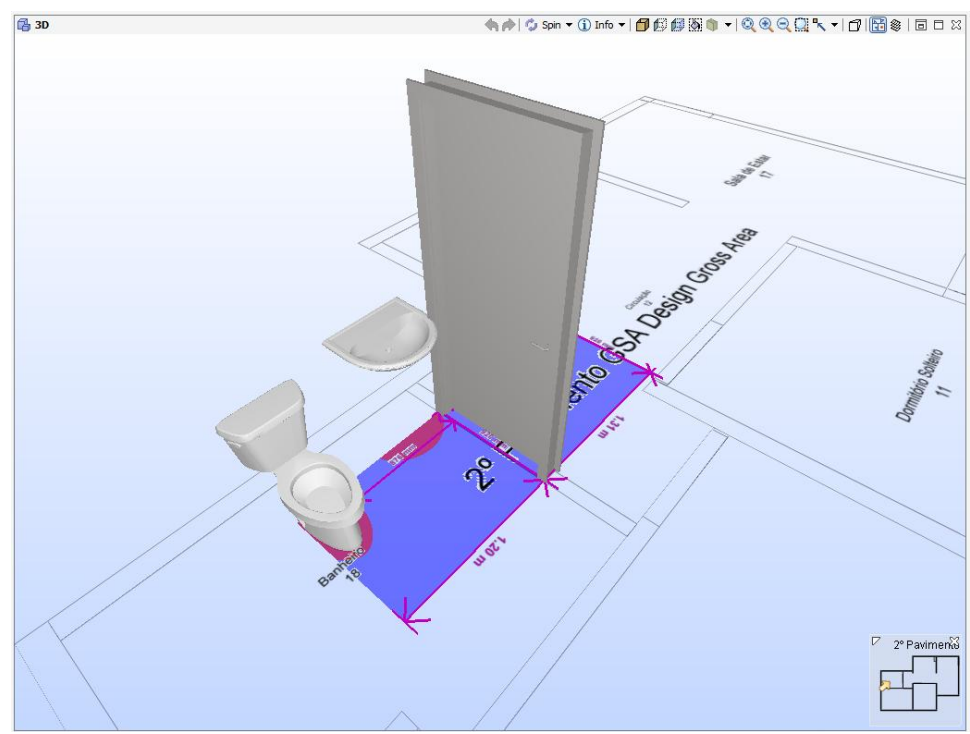

272 Fernandes, G. von der H.; Formoso, C. T.; Tzortzopoulos-Fazenda, P. 
Figura 10 - Área em frente à porta de um dos quartos

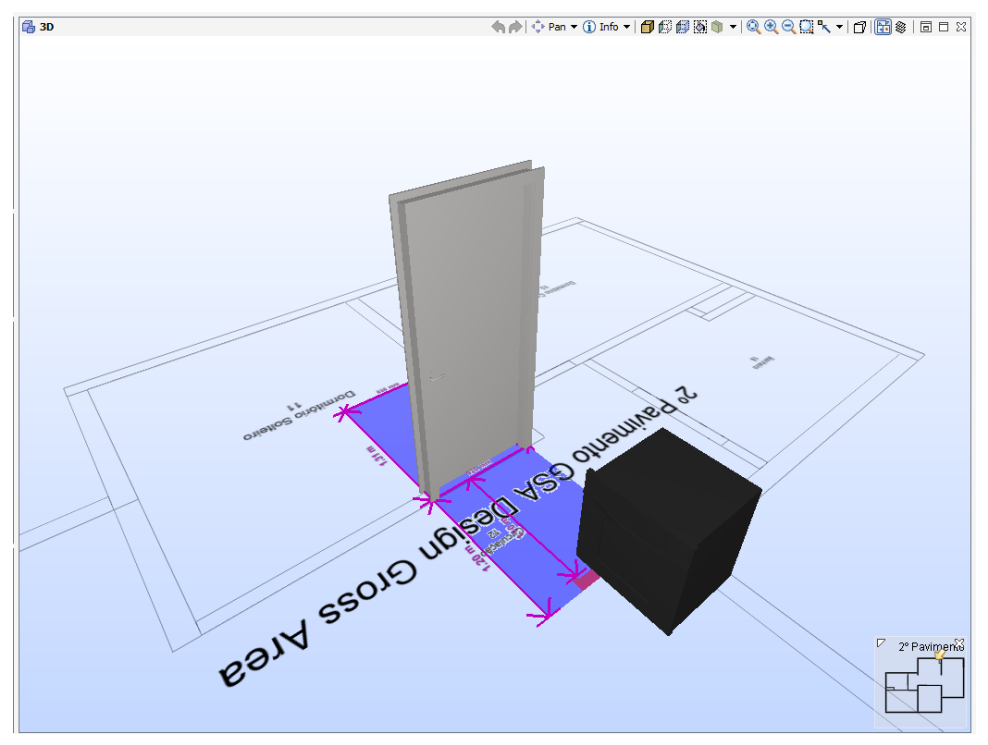

A comparação entre as duas formas de verificação indicou que a forma manual tem a vantagem de que o profissional tem a capacidade de verificação do todo, corrigindo uma situação de falso negativo da verificação automatizada. No caso específico, o sistema verificador identificou que não existia área de manobra na circulação do apartamento, contudo o giro poderia ser feito utilizando parte de outro ambiente, no caso a cozinha, como mostra a Figura 11.

\section{Estudo empírico 2}

As unidades habitacionais desse empreendimento possuíam $3 \mathrm{~m}^{2}$ além das dimensões mínimas, o que pode ter contribuído para facilitar o atendimento dos requisitos mínimos. Assim, a única inconsistência identificada na verificação automatizada era bastante simples: o projeto não atendia à quantidade mínima de tomadas na cozinha, conforme mostra a Figura 12. O profissional que realizou a verificação não identificou esse problema porque baseou sua análise no memorial descritivo, e não no projeto elétrico.

Contudo, o problema mais grave identificado não pôde ser checado pelo sistema automatizado em função de falta de um modelo de regra. Este se referia ao acesso das portas e à necessidade de manter $30 \mathrm{~cm}$ livres ao lado da porta ao acessá-la por fora do ambiente e $60 \mathrm{~cm}$ quando por dentro do ambiente, considerando que a porta abre para dentro do espaço. No acesso a um dos quartos, essas dimensões não foram respeitadas. Com o objetivo de atender à exigência no acesso ao banheiro, o projetista acabou criando um acesso estreito para a porta do quarto. Essa especificação foi revisada pelo Ministério das Cidades durante a etapa de elaboração desta pesquisa.

\section{Análise e reflexão}

O método proposto foi avaliado com base nos critérios de avaliação e critérios secundários, apresentados no métodode pesquisa.

\section{Utilidade}

Com relação à padronização das atividades de análise, a contribuição do método é clara por tornar os resultados de pelo menos parte das verificações independentes dos indivíduos que realizam essa tarefa. Por exemplo, no presente trabalho foram padronizados os critérios para verificação do módulo de giro dentro dos espaços e o espaço livre de um $1,20 \mathrm{~cm}$ em frente às portas, referentes aos itens 2.4 e 4.3 do Quadro 1. Outro aspecto da padronização diz respeito à forma como os projetos são apresentados para análise, uma vez que em um modelo BIM estão inseridas informações geométricas e semânticas, o que diminui a inconsistência entre distintos documentos. 
Figura 11 - Solução para a área de manobra utilizando espaço da cozinha

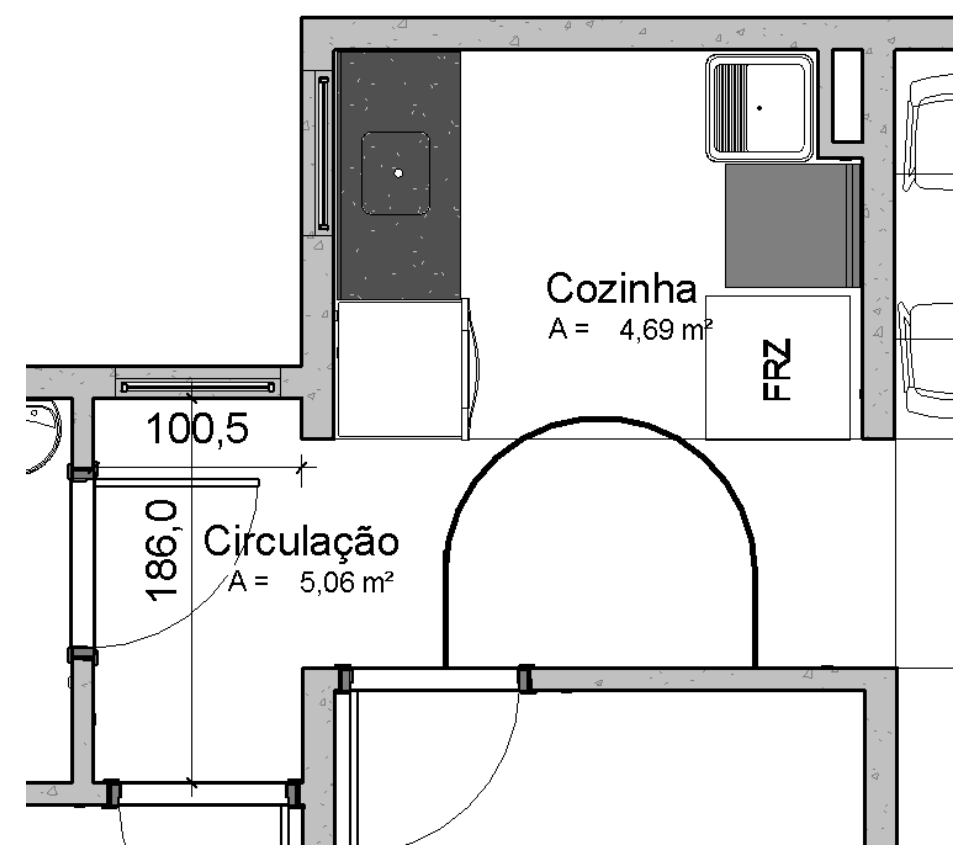

Figura 12 - Indicação da falta de tomadas na cozinha

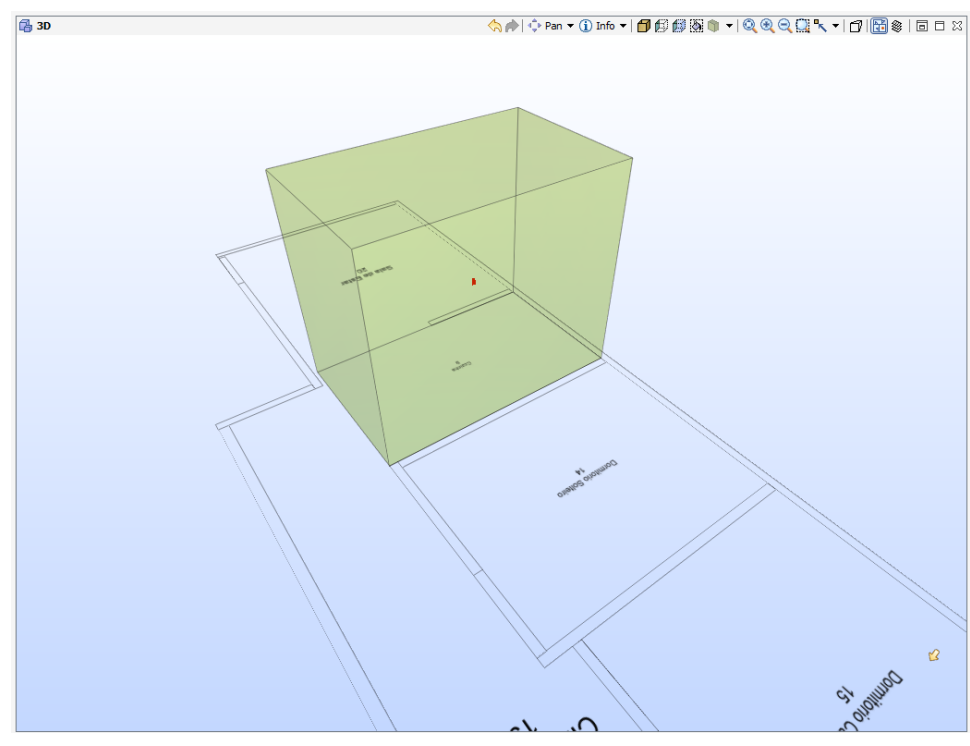

Outro benefício da verificação automatizada com o uso de BIM é o fato de que os profissionais responsáveis pelas análises e os próprios projetistas podem visualizar e manipular os modelos para encontrar erros de projeto e problemas de não conformidade em relação às especificações mínimas, e realizar as alterações necessárias mais rapidamente. No processo manual, a comunicação das inconsistências encontradas fica limitada ao relatório gerado pelo técnico responsável pela avaliação, e cabe ao projetista a tarefa de interpretar e identificar os problemas encontrados.

No que se refere à detecção dos problemas, o estudo apontou que uma parcela substancial dos requisitos mínimos (28\%) não pode ser verificada de forma automatizada por limitações do software ou pelo caráter subjetivo de alguns requisitos mínimos. Entretanto, para os itens que podem ser verificados pelo software, os resultados nos dois casos analisados mostraram-se relevantes e retornaram resultados semelhantes aos verificados manualmente. Deve-se destacar que alguns itens

274 Fernandes, G. von der H.; Formoso, C. T.; Tzortzopoulos-Fazenda, P. 
da verificação automatizada podem retornar falsos negativos ou positivos e, dessa forma, o processo demanda o acompanhamento ou revisão da verificação automatizada por profissional treinado.

\section{Aplicabilidade da solução}

O uso de BIM para a verificação do projeto em relação a requisitos mínimos permite aumentar o grau de automatização do fluxo das informações, reduzindo a necessidade de documentos impressos. Além disso, com o método diminui-se a probabilidade de erros humanos e o processo de avaliação torna-se mais objetivo, considerando que uma parcela substancial dos requisitos pode ser analisada por meio do software. Existem potenciais de ganhos ainda maiores ao considerar a possibilidade de transferir uma parte substancial do trabalho de verificação à própria equipe de projeto ou a profissionais especializados na compatibilização e verificação de projetos. Com isso se consegue diminuir prazos, pela eliminação de atividades e pela redução das iterações entre proponentes e avaliadores.

Com relação ao tempo dispendido na análise e à velocidade com que esta ocorre, em ambos os estudos empíricos os profissionais gastaram aproximadamente $4 \mathrm{~h}$ no trabalho de verificação. Por outro lado, o tempo para executar a modelagem do primeiro estudo empírico foi semelhante ao gasto na análise manual, $4 \mathrm{~h}$. Uma vez superadas as dificuldades da primeira modelagem, a segunda foi realizada com a metade de tempo. Eastman et al. (2011) aponta que o tempo de modelagem em BIM diminui à medida que o usuário automatiza algumas tarefas. Percebese, dessa forma, um ganho direto de tempo, além da possibilidade de o próprio projetista poder realizar verificações prévias, o que tende a tornar a verificação do órgão regulamentador ainda mais rápida.

No que se refere à adaptabilidade do método ao processo de verificação da Caixa, a análise dos mapas do processo de verificação de projetos atual indica que o método proposto poderia ser implementado sem grandes alterações. O software verificador mostrou-se efetivo em itens da verificação que não demandam a atenção de um verificador humano. Assim, a utilização direta da versão comercial do software verificador seria possível desde que bem definidas as regras checadas por este e as que demandariam atenção dos profissionais.

Contudo, percebeu-se que o software escolhido não é de fácil aprendizado, sendo seu uso pouco intuitivo e amigável aos usuários. Assim, para que seja utilizado por parte dos técnicos da Caixa, é necessário um esforço substancial de treinamento e o desenvolvimento de uma interface mais amigável, em português. Além disso, o estudo apontou algumas oportunidades de melhoria no software no que se refere à introdução ou flexibilização de algumas regras.

\section{Conclusões}

O presente trabalho propôs um método para a verificação automatizada de projetos em empreendimentos de habitação de interesse social (EHIS), que contém uma série de atividades, além da aplicação do software propriamente dito. Esta pesquisa buscou também apontar limitações na ferramenta de verificação de requisitos mais utilizada atualmente, ao mesmo tempo em que buscou contribuir com a compreensão da natureza dos requisitos em EHIS. Entre as contribuições desta pesquisa destaca-se o conhecimento da natureza dos requisitos mínimos considerados no programa Minha Casa, Minha Vida. Nesse sentido, a aplicação do método desenvolvido indicou que alguns requisitos não são expressos por meio de variáveis quantificáveis, fazendo com que o texto normativo dê margem a interpretações subjetivas.

Com relação aos benefícios do método, sua aplicação indicou que ele pode potencialmente contribuir para aumentar a conformidade em relação aos requisitos estabelecidos em normas e regulamentos, como também melhorar a consistência e a qualidade da apresentação dos projetos desenvolvidos por meio de um modelo BIM. Além disso, a comparação entre o método proposto e o processo tradicional, embora limitada a dois projetos, evidenciou grande redução no tempo de verificação, cuja economia pode compensar o esforço necessário para a modelagem BIM. Esses ganhos podem ser maiores caso a verificação seja realizada pelos próprios projetistas, como um teste de decisões de projeto ainda na fase de concepção do produto.

Considerando a necessidade de envolver um grande número de intervenientes do setor da construção (por exemplo, órgão financiador, organização promotora, empresa construtora, projetistas, entre outros), um ponto a ser considerado é a necessidade de usar sistemas computacionais que sejam interoperáveis, ou seja, que permitam a troca de informações sobre o modelo entre pacotes de softwares desenvolvidos por distintas empresas.

Além das contribuições foram identificadas limitações do método de verificação proposto, assim como na tecnologia empregada: 
(a) a verificação automatizada não dispensa o papel de um profissional de avaliação de projetos, cujo papel pode se tornar importante na medida em que ele pode focar nos aspectos mais subjetivos e complexos, que efetivamente requerem o conhecimento de especialistas. Segundo Eastman et al. (2011), a verificação manual e a automática devem ter um caráter complementar;

(b) observaram-se na ferramenta utilizada restrições no que se refere à formulação de regras. Além disso, algumas verificações requerem modelos BIM que contenham uma grande quantidade de detalhes (por exemplo, altura da maçaneta de portas), o que pode inviabilizar a verificação automatizada para alguns itens; e

(c) os arquivos IFC não carregam as informações que geram a geometria do modelo, e, dessa forma, o retorno dos resultados da verificação não pode ocorrer sem uma etapa de transposição entre a ferramenta de verificação e o modelador. Esta é sem dúvida uma limitação para a aplicação. O uso de pacotes fechados, ou seja, de um mesmo proprietário e que compartilhem as informações de modelagem, pode reduzir esse problema. Entretanto, essa possibilidade não é compatível com os princípios de isonomia da administração pública.

Com base na realização desta pesquisa, podem ser apontadas algumas oportunidades para pesquisas futuras:

(a) ampliar o método para a verificação de empreendimentos como um todo, incluindo áreas de uso comum e combinando requisitos de órgãos financiadores com os de outros órgãos verificadores, tais como prefeituras e corpo de bombeiros. Assim, o levantamento dos requisitos poderia buscar as dimensões e desempenhos exigidos para cada situação, resultando em um banco de regras mais amplo; e

(b) analisar as implicações nos fluxos de um sistema de verificação anexo aos programas modeladores BIM, como o SMC, e o da verificação realizada pelos próprios modeladores BIM. Isso poderia aprofundar a discussão sobre a melhor forma de realizar a verificação automatizada.

\section{Referências}

AEC3. International Code Council. Disponível em: <http://www.aec3.com/en/5/5_013_ICC.htm>. Acesso em: 15 ago. 2013.
ASSOCIAÇÃO BRASILEIRA DE NORMAS

TÉCNICAS. NBR 9050: acessibilidade a

edificações mobiliário, espaços e equipamentos urbanos. Rio de Janeiro, 2004

BALDAUF, J. P. Proposta de Método Para Modelagem de Requisitos de Clientes de Empreendimentos Habitacionais de Interesse Social Usando BIM. Porto Alegre, 2013.

Dissertação (Mestrado em Engenharia Civil) Programa de Pós-Graduação em Engenharia Civil, Universidade Federal do Rio Grande do Sul, Porto Alegre, 2013.

BORRMANN, A.; RANK, E. Query Support for BIMs Using Semantic and Spatial Conditions Topological Analysis of 3D Building Models Using a Spatial Query Language. Handbook of Research on Building Information Modeling and Construction Informatics: Concepts and Technologies, 2010.

BRASIL. Ministério das Cidades. Portaria n ${ }^{\circ} 168$, de 12 de abril 2013. Dispõe sobre as diretrizes gerais para aquisição e alienação de imóveis por meio de transferência de recursos ao Fundo de Arrendamento Residencial - FAR, no âmbito do Programa Nacional de Habitação Urbana - PNHU, integrante do Programa Minha Casa, Minha Vida PMCMV. Diário Oficial da União, Brasília, 13 de abril de 2013.

BRASIL.Ministério do Planejamento.Minha Casa, Minha Vida. Brasília, 2012. Disponível em: <http://www.pac.gov. br/minha-casa-minha-vida>. Acesso em: 20 out. 2012.

BRITISH STANDARDS INSTITUTION. B/555

Roadmap (august 2012 Update) - Design, Construction \& Operational Data \& Process Management for the Built Environment. BSI Standards Limited, 2012.

CAIXA. Financiamento Imobiliário Precisa de Novas Fontes de Recursos. 2014. Disponível em: $<\mathrm{http}: / /$

http://www20.caixa.gov.br/Paginas/Noticias/Notici a/Default.aspx?newsID=472>. Acesso em: 18 jun. 2015.

CHOI, J.; CHOI, J.; INHAN, K. Development of BIM-Based Evacuation Regulation Checking System For High-Rise and Complex Buildings.Automation in Construction, v. 46, p. 38-49, 2014.

EASTMAN, C. et al. Automatic Rule-Based Checking of Building Designs. Automation in Construction,v. 18, n. 8, dec. 2009. 
EASTMAN, C. et al. BIM Handbook: a guide to building information for owners, managers, designers, engineers and contractors. New Jersey: John Wiley \& Sons, 2011.

FIATECH. AutoCodes Project. Disponível em: $<$ http://www.fiatech.org/index.php/projects/activeprojects/162-active-projects/projectsmanagement/593-automated-code-plan-checkingtool-proof-of-concept>. Acesso em: 6 mar. 2014.

INSTITUTO DE PESQUISA ECONÔMICA APLICADA. Estimativas do Déficit Habitacional Brasileiro (2007-2011) Por Municípios (2010). Brasília, DF: Secretaria de Assuntos Estratégicos da Presidência da República, 2013.

KASANEN, E.; LUKKA, K.; SIITONEN, A. The Constructive Approach in Management Accounting Research. Journal of Management Accounting Research, p. 243-264, Fall 1993.

LAAKSO, M.; KIVINIEMI, A. The IFC Standard: a review of history, development, and standardization. ITcon, v. 17, p. 134-161, 2012.

LEE, J.-K. Building Environment Rule and Analysis (BERA) Language and Its Application For Evaluating Building Circulation and Spatial Program. Thesis Ph.D. Georgia Institute of Technology, 2011.

LEE, J.-K. et al. Development of Space Database For Automated Building Design Review Systems. Automation in Construction, v. 24, p. 203-212, 2012.

LEITE, F. et al. Analysis of Modeling Effort and Impact of Different Levels of Detail in Building Information Models. Automation in Construction, v. 20, n. 5, p. 601-609, 2011.

LUKKA, K. The Constructive Research Approach. In:OJALA, L.; HILMOLA, O-P. (Eds.). Case Study Research in Logistics. Series B1. Turku: Turku School of Economics and Business Administration, 2003.

MARCH, S. T.; SMITH, G. F. Design and Natural Science Research on Information Technology. Decision Suport Systems, v. 15, p. 251-266, 1995.

MARTINS, J. P.; MONTEIRO, A. LicA: a BIM based automated code-checking application for water distribution systems. Automation in Construction, v. 29, p. 12-23, Sept. 2012.

MAZAIRAC, W.; BEETZ, J. Towards a Framework For a Domain Specific Open Query Language For Building Information Models. In: EG-ICE WORKSHOP, 2012. Proceedings... 2012.
NAWARI, N. Automating Codes Conformance. Journal of Architectural Engineering, v. 18, n. 4, p. 315-323, dec. 2012a.

NAWARI, N. The Challenge of Computerizing Building Codes in BIM Environment. Computing in Civil Engineering, v. 1, p. 285-292, jun. 2012b.

NOVACITYNETS. Fornax, Plan Check Expert. 2013. Disponível em:

<http://www.novacitynets.com/fornax/brochure/en _fornax.pdf >. Acesso em: 15 ago. 2013.

PAUWELS, P. et al.A Semantic Rule Checking Environment For Building Performance Checking. Automation in Construction, v. 20, n. 5, p. 506518, aug. 2011.

SALAMA, D.; EL-GOHARY, N. Semantic Modeling For Automated Compliance Checking. Computing in Civil Engineering, p. 641-648, 2011.

SANGUINETTI, P. et al. General System Architecture For BIM: an integrated approach for design and analysis. Advanced Engineering Informatics, v. 26, p. 317-333, jan. 2012.

SAUSSURE, F. Curso de Lingüística Geral. São Paulo: Cultrix, 2004.

SHIGAKI, J.; TZORTZOPOULOS P. Ferramentas Para Implementação de Estratégias Colaborativas na Prática Integrada de Projetos de AEC Visando a Utilização de Building Information Modeling. In: SIMPÓSIO BRASILEIRO DE QUALIDADE DO PROJETO NO AMBIENTE CONSTRUÍDO, 3.; ENCONTRO BRASILEIRO DE TECNOLOGIA DE INFORMAÇÃO E COMUNICAÇÃO NA CONSTRUÇÃO, 6., Campinas, 2013. Anais... Porto Alegre: ANTAC, 2013.

SINGH, V.; NING, G. Towards an Integrated Generative Design Framework. Design Studies, v. 33, n. 2, p. 185-207, 2012.

SMITH, D. E.; TARDIF, M. Building

Information Modeling: a strategic implementation guide for architects, engineers, constructors, and real estate asset managers. New Jersey: John Wiley \& Sons, 2009.

STATSBYGG. Statsbygg BIM Manual. Version 1.2. Oslo: Statsbygg, 2011.

TAN, X.; HAMMAD, A.; FAZIO, P. Automated Code Compliance Checking For Building Envelope Design. Journal of Computing in Civil Engineering, v. 24, n. 2, mar./apr. 2010.

VAN AKEN, J. E. Management Research Based on the Paradigm of the Design Sciences: the quest for field-tested and grounded technological rules. Journal of Management Studies, v. 41, n. 2, mar. 2004. 
VAN STRIEN, P. J. Towards a Methodology of Psychological Practice. Theory \& Psychology, v. 7, n. 5, p. 683-700, 1997.

WIX, J.; KARLSHOJ, J. Information Delivery Manual: guide to components and development methods. BuildingSmart International, 2007. Disponível em: <http://iug.BuildingSmart.com/idms/development/ IDMC_004_1_2.pdf/at_download/file>. Acesso em: 10 jul. 2013.

YANG, Q. Z.; XU, X. Design Knowledge Modeling and Software Implementation For Building Code Compliance Checking. Building and Environment, v. 39, p. 689- 698, 2003.
ZHANG, J.; EL-GOHARY, N. Information transformation and automated reasoning for automated compliance checking in construction. Computing in Civil Engineering, v. 8, p. 701708, 2013.

ZHANG, S. et al. Building Information Modeling (BIM) and Safety: automatic safety checking of construction models and schedules. Automation in Construction, v. 29, n. 4, p. 183-195, jan. 2013.

ZHONG, B. T. et al. Ontology-Based Semantic Modeling of Regulation Constraint For Automated Construction Quality Compliance Checking.

Automation in Construction, v. 28, dec. 2012.

Guilherme von der Heyde Fernandes

Núcleo Orientado Para a Inovação da Edificação, Programa de Pós Graduacão Em Engenharia Civil | Universidade Federal do Rio Grande do Sul | Av. Osvaldo Aranha, 99, 3. Andar, Bom Fim | Porto Alegre - RS - Brasil | CEP 90035-190 | Tel.: (51) 3308-3518 | E-mail: guilherme@heyde.com.br

\section{Carlos Torres Formoso}

Núcleo Orientado Para a Inovação da Edificação, Programa de Pós Graduação em Engenharia Civil | Universidade Federal do Rio Grande do Sul | E-mail: formoso@ufrgs.br

\section{Patrícia Tzortzopoulos-Fazenda}

School of the Buil Environment | University of Salford | Maxwell Building, Greater Manchester | 54 | Salford - Inglaterra | Tel.: +(44) 16 1295-4284 | E-mail: p.tzortzopoulos@hud.ac.uk

\section{Revista Ambiente Construído}

Associação Nacional de Tecnologia do Ambiente Construído

Av. Osvaldo Aranha, $99-3^{\circ}$ andar, Centro

Porto Alegre - RS - Brasil

CEP 90035-190

Telefone: +55 (51) 3308-4084

Fax: +55 (51) 3308-4054

www.seer.ufrgs.br/ambienteconstruido

E-mail: ambienteconstruido@ufrgs.br

This is an open-access article distributed under the terms of the Creative Commons Attribution License.

278 Fernandes, G. von der H.; Formoso, C. T.; Tzortzopoulos-Fazenda, P. 